\title{
Analytical modelling of cutting forces in near-orthogonal cutting of titanium alloy
}

\section{Ti6Al4V}

\author{
Yun Chen ${ }^{1}$, Huaizhong $\mathrm{Li}^{2 *}$, and Jun Wang ${ }^{1}$ \\ ${ }^{1}$ School of Mechanical and Manufacturing Engineering, The University of New South Wales, \\ Sydney, NSW 2052, Australia \\ ${ }^{2}$ Griffith School of Engineering, Griffith University (Gold Coast Campus), Parklands Drive, \\ Southport Queensland 4214, Australia
}

\begin{abstract}
Titanium and its alloys are difficult to machine due to their high chemical reactivity with tool materials and low thermal conductivity. Chip segmentation caused by the thermoplastic instability is always observed in titanium machining processes, which leads to varied cutting forces and chip thickness etc. This paper presents an analytical modelling approach for cutting forces in near-orthogonal cutting of titanium alloy Ti6Al4V. The catastrophic shear instability in the primary shear plane is assumed as a semi-static process. An analytical approach is used to evaluate chip thicknesses and forces in near-orthogonal cutting process. The shear flow stress of the material is modelled by using the Johnson-Cook constitutive material law where the strain hardening, strain rate sensitivity and thermal softening behaviours are coupled. The thermal equations with non-uniform heat partitions along the tool-chip interface are solved by a finite difference method. The model prediction is verified with experimental data, where good agreement in terms of the average cutting forces and chip thickness is shown. A comparison of the predicted temperatures with published data obtained by using finite element method is also presented.
\end{abstract}

*Author to whom correspondence should be addressed. E-mail: lihuaizhong@gmail.com (Dr Huaizhong Li) 


\section{Keywords}

Cutting force model, titanium alloy, metal machining, constitutive material law, temperature distribution.

\section{Introduction}

Significant research efforts have been devoted to understanding the chip formation process and its generated cutting forces in metal machining. A comprehensive review given by Arrazola et al. ${ }^{1}$ indicates that there are generally three approaches in predictive performance models for machining: empirical, analytical and numerical. Empirical models are based on extensive experimentation ${ }^{2}$, while numerical models require a complex computational scheme $^{3}$. Relatively, analytical models for force modelling are easy to implement and can give much more insight into the physical mechanism in metal cutting. ${ }^{4}$ They use either minimum energy principle or slip line field theory for prediction of cutting forces and other outputs of interest. Minimum energy principle proposed by Ernst and Merchant ${ }^{5}$ considered the reaction in the shear plane and minimises the cutting energy to determine the shear angle which yields the direction of the shear plane. Slip-line field model has been improved by Oxley ${ }^{6}$ to predict the shear angle and cutting forces, considering the effects of strain, strain rate and temperature on the material flow stress. However, Oxley and his co-workers' achievements were mainly focused on mild carbon steels.

Titanium and its alloys, with their excellent strength-to-weight ratio, high fracture resistance characteristics and exceptional corrosion resistance, have been extensively used in aerospace, armor and biomedical industry. However, they are well known to be difficult to machine. Titanium and its alloys have strong affinities to many tool materials, which results in rapid tool wear. In addition, their low thermal conductivity give rise to a plastic instability localized in adiabatic shear bands and high temperatures at the tool-chip interface. 
Many research efforts have been dedicated to understand titanium machining processes. ${ }^{7,8} \mathrm{~A}$ common phenomenon observed in titanium machining is the formation of serrated chips., ${ }^{9}, 10$ It is generally accepted that the serrated chip formation is due to the catastrophic shearing in the primary shear zone when the effect of thermal softening predominates over that of the strain hardening. ${ }^{9,11}$ The formation of the serrated chips is a highly non-static cutting process with time-varied stress fields, chip velocities, and cutting forces etc. ${ }^{12}$ Investigations of such a dynamic process due to chip segmentation often employed finite element simulations of titanium machining. ${ }^{13-15}$ Chen et al. ${ }^{16}$ utilized a ductile failure model with consideration of thermoplastic instability to simulate Ti6Al4V machining. Calamaz et al. ${ }^{13}$ and Sima and Ozel $^{17}$ introduced temperature-dependent strain softening into the original Johnson-Cook constitutive model to numerically simulate titanium machining. Additionally, Wang et al. ${ }^{18}$ developed a hybrid cutting force model for titanium machining based on finite element simulation results and Oxley's theory. Although the use of finite element methods has obtained some successes in modelling the serrated chip formation and predicting cutting forces in titanium machining, it requires laborious computation work and is hard to be extended to 3-D cutting processes.

Ezugwu and Wang ${ }^{7}$ stated that high temperatures were generated during machining titanium alloys. The high temperatures have a critical influence on the tool performance and material properties. Komanduri and Hou ${ }^{11}$ developed a thermal model for the thermoplastic shear instability in machining of a titanium alloy and the critical cutting speed for the onset of the shear localization was predicted. Cotterell and Byrne ${ }^{19}$ used an empirical thermal model to predict average temperatures in the primary shear zone and tool rake face in orthogonal 
cutting of Ti6Al4V. Karpat and $\mathrm{Ozel}^{20}$ integrated a moving band heat source into Oxley’s machining theory for force predictions, whereas only easy-to-cut materials were concerned, not titanium alloys. Recently, Li and Wang ${ }^{21}$ introduced Kronenberg's thermal model ${ }^{22}$ in predicting cutting forces in milling of superalloy Inconel 718.

According to the study by Manyindo and Oxley ${ }^{23}$ on some features in the serrated chip formation, there are two distinct stages in one cycle of segmented chip formation, i.e., the ramp formation and catastrophic shear instability. During the ramp formation process, the region of low strain is formed (see Figure 1). The shear angle and chip velocity increase as the catastrophic shear instability stage progresses. The variation of the shear angle during the formation of the shear band was also observed by Sullivan et al. ${ }^{24}$ Sullivan et al argued that the maximum force was expected just when the shear plane was the longest (or the smallest shear angle) and vice versa. Furthermore, it was found by Manyindo and Oxley's study that the relationship between the instantaneous shear angle and chip velocity derived from the continuous chip formation was still applicative during the catastrophic shear stage, implying a semi-static state during the onset of the shear instability. It is unlikely to establish a closed form analytical force model to predict the time-varied cutting forces. ${ }^{8}$ However, if the variation of the shear angle at the catastrophic stage is neglected for simplicity, the cutting process can be considered approximately as a static process. Therefore, Oxley's strain-rate and strain distributions are still applicable for the catastrophic process. The calculated forces or temperatures based on Oxley's theory can be thought as the average values of the timevaried results. 
The objective of this paper is to provide an analytical approach for the modelling of the titanium machining process. Based on the experimental observations by Manyindo and Oxley $^{23}$, it is assumed that the chip formation process of titanium machining can be considered to be semi-static, and Oxely's predictive machining theory is still applicable for the catastrophic process. The constitutive Johnson-Cook material model is integrated into Oxely's theory. To estimate the temperature along the tool-chip interface, a temperature model based on the work of Lazoglu and Altintas ${ }^{25}$ is introduced. The model predictions are compared with experimental process data under various cutting conditions for verification.

\section{Model development}

Basic geometric relationships in cutting

Oxley's predictive machining theory on orthogonal cutting ${ }^{6}$ is based on a model of chip formation derived from the slip-line field analysis and the strain rate analysis of experimental flow fields. According to Oxley ${ }^{6}$, the basic relationships in orthogonal cutting can be obtained from the cutting geometry (Figure 2) and expressed as

$$
\begin{aligned}
& t_{2}=\frac{t_{1} \cos \left(\phi_{n}-\alpha_{n}\right)}{\sin \phi_{n}} \\
& F_{c}=R \cos \left(\lambda_{n}-\alpha_{n}\right), \quad F_{t}=R \sin \left(\lambda_{n}-\alpha_{n}\right), \quad F_{s}=k_{A B} l w \\
& F=R \sin \lambda_{n}, \quad N=R \cos \lambda_{n} \\
& R=\frac{F_{s}}{\cos \left(\lambda_{n}+\phi_{n}-\alpha_{n}\right)}=\frac{k_{A B} t_{1} w}{\sin \phi_{n} \cos \left(\lambda_{n}+\phi_{n}-\alpha_{n}\right)} \\
& V=U \frac{\sin \phi_{n}}{\cos \left(\phi_{n}-\alpha_{n}\right)}, \quad V_{s}=U \frac{\cos \alpha_{n}}{\cos \left(\phi_{n}-\alpha_{n}\right)}
\end{aligned}
$$




$$
\lambda_{n}=\theta_{n}-\phi_{n}+\alpha_{n}
$$

where $t_{1}$ and $t_{2}$ are the uncut and cut chip thicknesses respectively, $w$ is the width of cut, $l$ is the length of the shear plane $A B, k_{A B}$ is the shear flow stress along $A B, V_{s}, V$ and $U$ are the shear, chip and cutting velocities respectively, and all forces and angles are shown in Figure 2.

\section{Constitutive model for workpiece material}

Oxley's analytical model used piecewise, high order curve fitting equations for low carbon steels to describe the relationship between the velocity-modified temperature and shear flow stress. Unfortunately, such a material model is available only for a few metals, mainly low carbon steels. For a wide range of other engineering materials such as titanium alloys, there is no such documented representation that can be used as the inputs for Oxley's predictive machining theory ${ }^{21}$. Alternatively, the constitutive model of Johnson and $\operatorname{Cook}^{26}$ is easy to be determined and has representations for many materials (Table 1). It describes materials subjected to large strains, high strain rates and high temperatures which are similar to the conditions in metal cutting. The material constants in the model can be obtained from torsion tests over a wide range of strain rates, static tensile tests, dynamic Hopkinson bar tests and Hopkinson bar tests at elevated temperatures. It provides an empirical relationship for the flow stress $\sigma$ of a material as

$$
\sigma=\left(A+B \varepsilon^{n}\right)\left(1+C \ln \left(\frac{\dot{\varepsilon}}{\dot{\varepsilon}_{0}}\right)\right)\left(1-\left(\frac{T-T_{r}}{T_{m}-T_{r}}\right)^{m}\right)
$$

where $\varepsilon, \dot{\varepsilon}$ and $\dot{\varepsilon}_{0}$ are the equivalent strain, equivalent strain rate, and reference strain rate (usually $1 \mathrm{~s}^{-1}$ ), respectively. $T$ is the instantaneous temperature of the material, $T_{r}$ is the 
reference temperature and $T_{m}$ is the melting temperature. $A, B, C, n$, and $m$ are constants obtained by material tests.

\section{Stresses in the primary zone}

Since the cutting process is assumed to be a plain strain condition, according to the Von Mises criterion, the equivalent strain and strain rate at plane $A B$ can be given as

$$
\varepsilon_{A B}=\frac{\cos \alpha_{n}}{2 \sqrt{3} \cos \left(\phi_{n}-\alpha_{n}\right) \sin \phi_{n}}, \dot{\varepsilon}_{A B}=C_{0} \frac{V_{s}}{\sqrt{3 l}}
$$

where $C_{0}$ is the ratio of the length $l$ to the thickness of the primary shear zone.

It is assumed that the material in the catastrophic shear zone is immediately and uniformly heated up. Heat due to the adiabatic shear instability is almost concentrated in the narrow localized shear band with little heat conducted into the work material and chip. Therefore, the average temperature $T_{A B}$ of the shear plane can be estimated using the below relationship ${ }^{27}$

$$
T_{A B}=F_{s} V_{s} \frac{1}{\rho S t_{1} U w}+T_{r}
$$

where $\rho$ and $S$ are the density and specific heat of the work material respectively.

Therefore, the equivalent shear stress $k_{A B}$ at plane $A B$ by using the Johnson-Cook model can be determined as

$$
k_{A B}=\frac{1}{\sqrt{3}}\left(A+B \varepsilon_{A B}{ }^{n}\right)\left(1+C \ln \left(\frac{\dot{\varepsilon}_{A B}}{\dot{\varepsilon}_{0}}\right)\right)\left(1-\left(\frac{T_{A B}-T_{r}}{T_{m}-T_{r}}\right)^{m}\right)
$$

As shown in Appendix 2, the angle $\theta_{n}$ between the resultant force $R$ and plane $A B$ is given by

$$
\theta_{n}=\tan ^{-1}\left(1+2\left(\frac{\pi}{4}-\phi_{n}\right)-C_{0} \frac{B \varepsilon_{A B}{ }^{n}}{A+B \varepsilon_{A B}{ }^{n}}\right)
$$

Similarly, the normal stress $\sigma_{N}{ }^{\prime}$ at point $A$ is (see Appendix 2)

$$
\sigma_{N}{ }^{\prime}=k_{A B}\left(1+\frac{\pi}{4}-2 \alpha_{n}-2 C_{0} \frac{B \varepsilon_{A B}^{n}}{A+B \varepsilon_{A B}^{n}}\right)
$$




\section{Stresses at the tool-chip interface}

The shear flow stress $k_{\text {chip }}$ at the tool-chip interface can be calculated as

$$
k_{\text {chip }}=\frac{1}{\sqrt{3}} A\left(1+C \ln \left(\frac{\dot{\varepsilon}_{\text {int }}}{\dot{\varepsilon}_{0}}\right)\right)\left(1-\left(\frac{T_{\text {int }}-T_{r}}{T_{m}-T_{r}}\right)^{m}\right.
$$

According to Oxley ${ }^{6}$, the maximum equivalent shear strain rate $\dot{\varepsilon}_{\text {int }}$ and shear strain $\varepsilon_{\text {int }}$ at the tool-chip interface is

$$
\dot{\varepsilon}_{\text {int }}=\frac{V}{\sqrt{3} \delta t_{2}}, \quad \varepsilon_{\text {int }}=\frac{h}{\sqrt{3} \delta t_{2}}
$$

where $\delta$ is the ratio of tool-chip interface plastic zone thickness to chip thickness. $h$ is the tool-chip interface contact length and can be given by (see Appendix 2)

$$
h=\frac{t_{1} \sin \theta_{n}}{\cos \lambda_{n} \sin \phi_{n}}\left\{1+\frac{C_{0} \frac{B \varepsilon_{A B}{ }^{n}}{A+B \varepsilon_{A B}{ }^{n}}}{3\left[1+2\left(\frac{\pi}{4}-\phi_{n}\right)-C_{0} \frac{B \varepsilon_{A B}{ }^{n}}{A+B \varepsilon_{A B}{ }^{n}}\right]}\right\}
$$

The average tool-chip interface temperature $T_{\text {int }}$ is evaluated using an analytical model of the steady state temperature field in metal cutting by Lazoglu and Altintas ${ }^{25}$. Polar coordinates are employed for the heat equilibrium equation of the tool, whereas Cartesian coordinates are used for the chip. The heat flow conducts in two directions in both the chip and tool, and additionally, there is one-dimensional mass transfer along the chip flow direction in the chip. Accordingly, the heat balance equations of the discrete zone in Figure 3(a) for the chip and tool can be written as

$$
\begin{aligned}
& \frac{\partial^{2} T_{c}}{\partial x^{2}}+\frac{\partial^{2} T_{c}}{\partial y^{2}}+\frac{\dot{q}_{c}}{K}=\frac{\rho S}{K} \frac{\partial T_{c}}{\partial t}=\frac{\rho S}{K} V \frac{\partial T_{c}}{\partial x} \\
& \frac{\partial^{2} T_{t}}{\partial r^{2}}+\frac{1}{r} \frac{\partial^{2} T_{t}}{\partial r}+\frac{1}{r^{2}} \frac{\dot{q}_{t}}{\partial \varphi^{2}}+\frac{\dot{q}_{t}}{K_{t}}=0
\end{aligned}
$$


where $T_{c}$ and $T_{t}$ represent the chip and tool temperature fields, $\dot{q}_{c}$ and $\dot{q}_{t}$ are the instantaneous rates of heat generation per unit volume for the chip and tool respectively, and $K$ and $K_{t}$ are the thermal conductivities for the work material and tool respectively. In this thermal model, $K, K_{t}$ and $S$ are considered to be constant, although they are dependent on temperature.

Using a differential form, the above two equations for each node in the chip and tool in Figure 3(b) and Figure 3(c) respectively become

$$
\begin{aligned}
& \frac{T_{c(i+1, j)}+T_{c(i-1, j)}-2 T_{c(i, j)}}{\Delta x^{2}}+\frac{T_{c(i, j+1)}+T_{c(i, j-1)}-2 T_{c(i, j)}}{\Delta y^{2}}+\frac{\dot{q}_{c(i, j)}}{K}=\frac{\rho S}{K} V \frac{T_{c(i+1, j)}-T_{c(i, j)}}{\Delta x} \\
& \frac{T_{t(i+1, k)}+T_{t(i-1, k)}-2 T_{t(i, k)}}{\Delta r^{2}}+\frac{T_{t(i+1, k)}-T_{t(i-1, k)}}{2 r \Delta r}+\frac{T_{t(i, k+1)}+T_{t(i, k-1)}-2 T_{t(i, k)}}{r^{2} \Delta \varphi^{2}}+\frac{\dot{q}_{t(j, k)}}{K_{t}}=0
\end{aligned}
$$

Assuming a plane friction heat source with a uniform heat intensity distribution and nonuniform heat partition ratios along the tool-chip interface, the localized heat generation rates $\dot{q}_{c(i, j)}$ and $\dot{q}_{t(i, k)}$ in the differential chip and tool control zone from the friction heat source along the chip-tool contact length are obtained as

$$
\begin{aligned}
& \dot{q}_{c(i, j)}=\frac{\left(1-B_{i}\right) F V d x}{h w} \text { if and only if } 1 \leq i \leq N_{x}+1, j=1 \\
& \dot{q}_{t(i, k)}=\frac{B_{i} F V d x}{h w} \quad \text { if and only if } 1 \leq i \leq N_{x}+1, k=1
\end{aligned}
$$

where $B_{i}$ represents the proportion of the friction heat flowing into the tool at the $i$ th nodal point along the tool-chip interface, and $h$ is the tool-chip contact length. The nodes, other than the nodes along the tool-chip contact interface, will physically have no heat generation input and thus $\dot{q}_{c(i, j)}$ and $\dot{q}_{t(i, k)}$ are set to zero for all these nodes.

Collecting the above equilibrium equations for all nodes, compact matrix forms can be obtained for both the chip and tool 
where $\left[T_{c}\right]$ and $\left[E_{c}\right]$ are the temperature and heat generation arrays with equal size of $\left(N_{y}+1\right)\left(N_{x}+1\right)$ for the chip respectively, $\left[T_{t}\right]$ and $\left[E_{t}\right]$ are arrays for the tool with size of $\left(N_{r}+1\right)\left(r_{\max } / d r+1\right)-N_{r}$, and $\left[D_{c}\right]$ and $\left[D_{t}\right]$ are the square coefficient matrices for the chip and tool determined from equation (18) and equation (19) respectively. Given $B_{i}$, the temperature arrays $\left[T_{c}\right]$ and $\left[T_{t}\right]$ can simply be obtained as

$$
\left[T_{c}\right]=\left[D_{c}\right]^{-1}\left[E_{c}\right], \quad\left[T_{t}\right]=\left[D_{t}\right]^{-1}\left[E_{t}\right]
$$

To solve the equilibrium equation (22), an iterative process is needed to determine $B_{i}$ as shown in Figure 4. The heat proportions $B_{i}$ are initially assigned with values between 0 and 1 . The tool and chip temperature fields can be determined based on the initial assignments of $B_{i}$. If temperatures of the corresponding tool and chip nodal points, at which the tool and chip are in contact, are different to each other, then the heat partition values for the corresponding nodal points need to be modified according to the following formulation

$$
d B_{i}=2 G \frac{T_{c(i, 1)}-T_{t(i, 1)}}{T_{c(i, 1)}+T_{t(i, 1)}}
$$

where $G$ is a value between 0 and 1 and is used to guarantee the convergence. If the maximum of $d B_{i}$ is larger than a certain defined value, a new $B_{i}$ is assigned as

$$
B_{i}=B_{i}+d B_{i}
$$

These new heat partitions are used to solve the heat balance equations again. The iterative solutions end, until the maximum of $d B_{i}$ is less than a predefined value. Therefore, the temperature fields of the tool and chip can be determined with the non-uniform heat partitions. The average temperature along the tool-chip interface is found as 


$$
T_{\mathrm{int}}=\sum_{i=1}^{N_{x}+1} T_{c(i, 1)}
$$

Assuming a uniform stress distribution over the tool-chip interface, the average shear stress $\tau_{\text {int }}$ and normal stress $\sigma_{N}$ at the interface are found from the equations

$$
\tau_{\text {int }}=\frac{F}{h w}, \sigma_{N}=\frac{N}{h w}
$$

\section{Model integration}

To obtain cutting forces and other outputs, the Johnson-Cook material model and thermal model based on Lazoglu and Altintas’s work are integrated into Oxley’s analytical theory. There are three unknown parameters of importance in the above analysis for orthogonal cutting process, i.e., $\phi_{n}, C_{0}$ and $\delta$. An iteration calculation approach in Figure 5 is employed to determine them. The shear angle $\phi_{n}$ is determined by the fact that $k_{c h i p}$ as a function of strain-rate, strain and temperature should be equal to $\tau_{\text {int }}$. If there is more than one $\phi_{n}$ that makes $\tau_{\text {int }}$ and $k_{\text {chip }}$ equal, the highest $\phi_{n}$ is chosen. $C_{0}$ is searched iteratively to satisfy the force equilibrium that the average normal stress $\sigma_{N}$ from equation (27) should be equal to $\sigma_{N}{ }^{\prime}$ as a function of $C_{0}$ from equation (12). The last unknown $\delta$ is obtained from the minimum work process principle, which means to take the value of $\delta$ when $F_{C}$ is the minimum.

\section{Model verification}

Experimental results on turning titanium alloy Ti6Al4V were used to verify the proposed model. The cutting parameters are listed in Table 2. A Colchester Tornado A50 CNC Lathe was used in the cutting experiments. The cutting forces were measured using a Kistler piezoelectric dynamometer Type 9257B (Figure 5(b)). The cylinder Ti6Al4V workpiece was 
prepared with several circular rings of $2 \mathrm{~mm}$ thickness as shown in Figure 6(a). The interval between two neighbouring rings was set as $2 \mathrm{~mm}$, such that only one ring is cut at any time and the cutter nose is not engaged in cutting. Dry turning was carried out using SECO carbide inserts WNMG-080408T-MF1. When the insert is fixed in the tool holder, the rake and inclination angles are both $-6^{\circ}$ and the side cutting edge angle is $-5^{\circ}$. The inclination angle is quite small, and therefore the cutting process can approximately be considered as orthogonal cutting.

In the experiments, cyclic cutting forces were observed which agrees with the assumption that titanium cutting process is a non-static process due to the serrated chip formation. Figures 7 (a) and (b) present the variations of the maximum and minimum measured forces $F_{C}$ and $F_{t}$ with respect to the cutting speed, as well as the predicted forces. It can be seen that increment of the cutting speed has little influence on the average values of the measured forces. $F_{c}$ and $F_{t}$ fluctuate slightly at about 520 and $285 \mathrm{~N}$ respectively as the cutting speed increases from 40 to $100 \mathrm{~m} / \mathrm{min}$. However, the differences between the maximum and minimum values of $F_{c}$ and $F_{t}$ decrease with the increase of the cutting speed. The predicted forces, which approximate the average cutting forces, are in the ranges determined by the measured maximum and minimum values, indicating a close agreement between the predicted and measured results. Additionally, the predicted forces $F_{c}$ and $F_{t}$ show a slight downward trend when the cutting speed increases, which is believed to be caused by the effect of the thermal softening. Figure 7(c) presents the measured and predicted chip thicknesses. Due to the chip segment formation, the chip thickness in a single chip can vary significantly. The maximum and minimum chip thicknesses at cutting speed $80 \mathrm{~m} / \mathrm{min}$ and feed rate $0.15 \mathrm{~mm} / \mathrm{rev}$ are 0.193 and $0.736 \mathrm{~mm}$ respectively. It is interesting to observe that the minimum chip thicknesses for all cutting speeds investigated are smaller than the feed 
rate $0.15 \mathrm{~mm} / \mathrm{rev}$, and the maximum chip thicknesses vary close to the feed rate. The predicted average chip thicknesses are quite close to the maximum chip thicknesses. According to equation (1), a small chip thickness ratio $t_{2} / t_{1}$ implies a large shear angle. The largest shear angle predicted is $42.4^{\circ}$ at cutting speed $100 \mathrm{~m} / \mathrm{min}$ and feed rate $0.15 \mathrm{~mm} / \mathrm{rev}$. Such a large shear angle in titanium machining can also be found in the simulation results presented by Ginting and Nouari. ${ }^{28}$

The performance of the proposed model is also examined under different feed rates as shown in Figure 8. Unlike the cutting speed, the increase of the feed rate increases the gaps between the maximum and minimum force values. It shows a similar variation trend of the simulated and measured cutting forces versus the increase of the feed rate. The predicted forces perform well in representing the average values of the measured forces. The predicted average chip thicknesses are between the measured maximum and minimum chip thicknesses as shown in Figure 8(c).

Figure 9(a) illustrates the variation of the heat proportion $B_{i}$ into the tool vs distance along the cutting edge. It indicates that close to the end of the tool-contact length most of the hear flows into the tool. Similar results can also be found in the works by Karpat and Ozel ${ }^{20}$ and Lazoglu and Altintas ${ }^{25}$. Lazoglu and Altintas argued that the heat proportion $B_{i}$ larger than 1 was due to the fact that some of the chip heat is transmitted to the tool in order to balance relatively cold tool backside temperature. The temperature field at cutting speed $60 \mathrm{~m} / \mathrm{min}$ and feed rate $0.15 \mathrm{~mm} /$ toot is given in Figure 9(b)). The maximum tool-chip interface temperature predicted is $670{ }^{\circ} \mathrm{C}$. Table 2 lists the predicted maximum temperatures under different cutting conditions. It can be seen that the maximum tool-chip interface temperatures increase along with the cutting speed or feed rate. 
The proposed model is further assessed by comparing the predictions with the results given by Sima and $\mathrm{Ozel}^{17}$ for orthogonal cutting of titanium alloy Ti6Al4V. In the experiments, cutting tools were with rake angles $0^{\circ}$ and $5^{\circ}$ and relief angles $11^{\circ}$ and $6^{\circ}$ respectively. The cutting conditions are given in Table 3. Figure 10(a) shows that the predicted forces agree quite well with the measured results, with the largest percentage error $20 \%$ for $F_{t}$ at test 4 . The model also performs well in predicting the average chip thickness, as shown in Figure 10(b).

Figure 11 shows a comparison of the maximum tool-chip interface temperatures predicted by the proposed model and by a finite element method (Sima and Ozel ${ }^{17}$ ). It is found that the temperatures predicted by the proposed model are slightly larger than that by Sima and Ozel. This could be due to the use of a modified Johnson-Cook material model with a flow softening effect in Sima and Ozel's work. A case of the simulated temperature field is shown in Figure 12, in which the highest temperature occurs at about $0.12 \mathrm{~mm}$ away from the cutting edge.

The above comparison shows that the proposed model by extending Oxley's theory developed for continuous chip formation to serrated chip formation can be used to predict the average cutting forces and chip thickness. It should be noted that more research efforts, such as to establish more reasonable strain and stress fields particularly for the serrated chip formation, are still needed to improve the model applicability and accuracy. 


\section{Conclusions}

The serrated chip formation due to the thermoplastic instability is often observed in titanium machining. The chip segmentation affects the machining process, and gives rise to periodic cutting forces, chip velocities, etc. In this study, the catastrophic shear stage is considered to be semi-static, and fundamentals of Oxley's predictive machining theory derived from the continuous chip formation are assumed to be still applicable at this stage. The Johnson-Cook constitutive material law is integrated into Oxely's theory to represent the shear flow stress of titanium alloy Ti6Al4V under high strains, strain rates and temperatures. To evaluate the high temperatures generated in titanium machining, a thermal model with non-uniform heat partitions along the tool-chip interface has been introduced. Thermal balance equations for the chip and tool are solved by the finite difference method.

The predicted cutting forces and chip thicknesses under various cutting conditions are examined, and the proposed model is capable to predict the average values of the experimental data with considerable accuracy. Additionally, the predicted maximum toolchip interface temperatures agree well with those predicted by using finite element method.

\section{References}

1. Arrazola PJ, Özel T, Umbrello D, Davies M and Jawahir IS. Recent advances in modelling of metal machining processes. CIRP Annals - Manufacturing Technology. 2013; 62: 695-718.

2. Budak E, Armarego EJA and Altintas Y. Prediction of Milling Force Coefficients From Orthogonal Cutting Data. Journal of Engineering for Industry. 1996; 118: 216-24. 
3. Jin X and Altintas Y. Prediction of micro-milling forces with finite element method. Journal of Materials Processing Technology. 2012; 212: 542-52.

4. Huang Y and Liang SY. Cutting forces modeling considering the effect of tool thermal property—application to CBN hard turning. International Journal of Machine Tools and Manufacture. 2003; 43: 307-15.

5. Ernst $\mathrm{H}$ and Merchant $\mathrm{M}$. Chip formation, friction, and high quality machined surfaces. Surface Treatment of Metals (American Society for Metals). 1941; 29: 299-378.

6. Oxley PLB. The Mechanics of Machining: An Analytical Approach to Assessing Machinability. England: Ellis Horwood Ltd., 1989.

7. Ezugwu EO and Wang ZM. Titanium alloys and their machinability-a review. Journal of Materials Processing Technology. 1997; 68: 262-74.

8. Yang $\mathrm{X}$ and Liu CR. Machining titanium and its alloys. Machining Science and Technology. 1999; 3: 107-39.

9. Komanduri R. Some clarifications on the mechanics of chip formation when machining titanium alloys. Wear. 1982; 76: 15-34.

10. Barry J, Byrne G and Lennon D. Observations on chip formation and acoustic emission in machining Ti-6Al-4V alloy. International Journal of Machine Tools and Manufacture. 2001; 41: 1055-70.

11. Komanduri R and Hou Z-B. On thermoplastic shear instability in the machining of a titanium alloy (Ti-6Al-4V). Metall and Mat Trans A. 2002; 33: 2995-3010.

12. Fang N, Yang J and Liu N. Analytical predictive modeling of serrated chip formation in high speed machining of 7075-T6 aluminum alloy. 2004 ASME International Mechanical 
Engineering Congress and Exposition. Anaheim, CA, United states: American Society of Mechanical Engineers, 2004, p. 769-77.

13. Calamaz M, Coupard D and Girot F. A new material model for 2D numerical simulation of serrated chip formation when machining titanium alloy Ti-6Al-4V. International Journal of Machine Tools and Manufacture. 2008; 48: 275-88.

14. Hua J and Shivpuri R. Prediction of chip morphology and segmentation during the machining of titanium alloys. Journal of Materials Processing Technology. 2004; 150: 12433.

15. Obikawa $\mathrm{T}$ and Usui E. Computational machining of titanium alloy - finite element modeling and a few results. Journal of Manufacturing Science and Engineering, Transactions of the ASME. 1996; 118: 208-15.

16. Chen G, Ren C, Yang X, Jin X and Guo T. Finite element simulation of high-speed machining of titanium alloy (Ti-6Al-4V) based on ductile failure model. Int $J$ Adv Manuf Technol. 2011; 56: 1027-38.

17. Sima $\mathrm{M}$ and Ozel T. Modified material constitutive models for serrated chip formation simulations and experimental validation in machining of titanium alloy Ti-6Al-4V. International Journal of Machine Tools and Manufacture. 2010; 50: 943-60.

18. Wang ZG, Rahman M, Wong YS and Li XP. A hybrid cutting force model for highspeed milling of titanium alloys. CIRP Annals - Manufacturing Technology. 2005; 54: 71-4.

19. Cotterell $\mathrm{M}$ and Byrne G. Characterisation of chip formation during orthogonal cutting of titanium alloy Ti-6Al-4V. CIRP Journal of Manufacturing Science and Technology. 2008; 1: 81-5. 
20. Karpat Y and Özel T. Predictive Analytical and Thermal Modeling of Orthogonal Cutting Process-Part I: Predictions of Tool Forces, Stresses, and Temperature Distributions. Journal of Manufacturing Science and Engineering. 2005; 128: 435-44.

21. Li H and Wang J. A cutting forces model for milling Inconel 718 alloy based on a material constitutive law. Proceedings of the Institution of Mechanical Engineers, Part C: Journal of Mechanical Engineering Science. 2013; 227: 1761-75.

22. Kronenberg. Machining science and application theory and practice for operation and development of machining processes. Oxford: Pergramon Press, 1966.

23. Manyindo BM and Oxley PLB. Modelling the catastrophic shear type of chip when machining stainless steel. Proceedings of the Institution of Mechanical Engineers Part C Mechanical engineering science. 1986; 200: 349-58.

24. Sullivan KF, Wright PK and Smith PD. Metallurgical appraisal of instabilities arising in machining. 1978; 5: 181-9.

25. Lazoglu I and Altintas Y. Prediction of tool and chip temperature in continuous and interrupted machining. International Journal of Machine Tools and Manufacture. 2002; 42: 1011-22.

26. Johnson Gr and Cook WH. A Constitutive Model and Data for Metals Subjected to Large Strains, High Strain Rates and High Temperatures. Proceedings of the 7th International Symposium on Ballistics 1983: 7.

27. Tlusty G. Manufacturing processes and equipment. Upper Saddle River, NJ: Prentice Hall, 2000. 
28. Ginting A and Nouari M. Experimental and numerical studies on the performance of alloyed carbide tool in dry milling of aerospace material. International Journal of Machine Tools and Manufacture. 2006; 46: 758-68.

29. Jaspers SPFC and Dautzenberg JH. Material behaviour in conditions similar to metal cutting: flow stress in the primary shear zone. Journal of Materials Processing Technology. 2002; 122: 322-30.

30. Meyer Jr HW and Kleponis DS. Modeling the high strain rate behavior of titanium undergoing ballistic impact and penetration. International Journal of Impact Engineering. 2001; 26: 509-21.

\section{Appendix 1}

Notation

A plastic equivalent strain in Johnson-Cook constitutive model

$A_{s}, A_{f} \quad$ areas of the shear plane and friction plane

B strain related constant in Johnson-Cook constitutive model

$B_{i} \quad$ proportion of the friction heat flowing into the tool at the $i$ th nodal point

C strain-rate sensitivity constant in Johnson-Cook constitutive model

$C_{s} \quad$ side cutting edge angle

$C_{0} \quad$ ratio of thickness of primary zone and length of $A B$

$F_{s}, F \quad$ shear and friction forces 


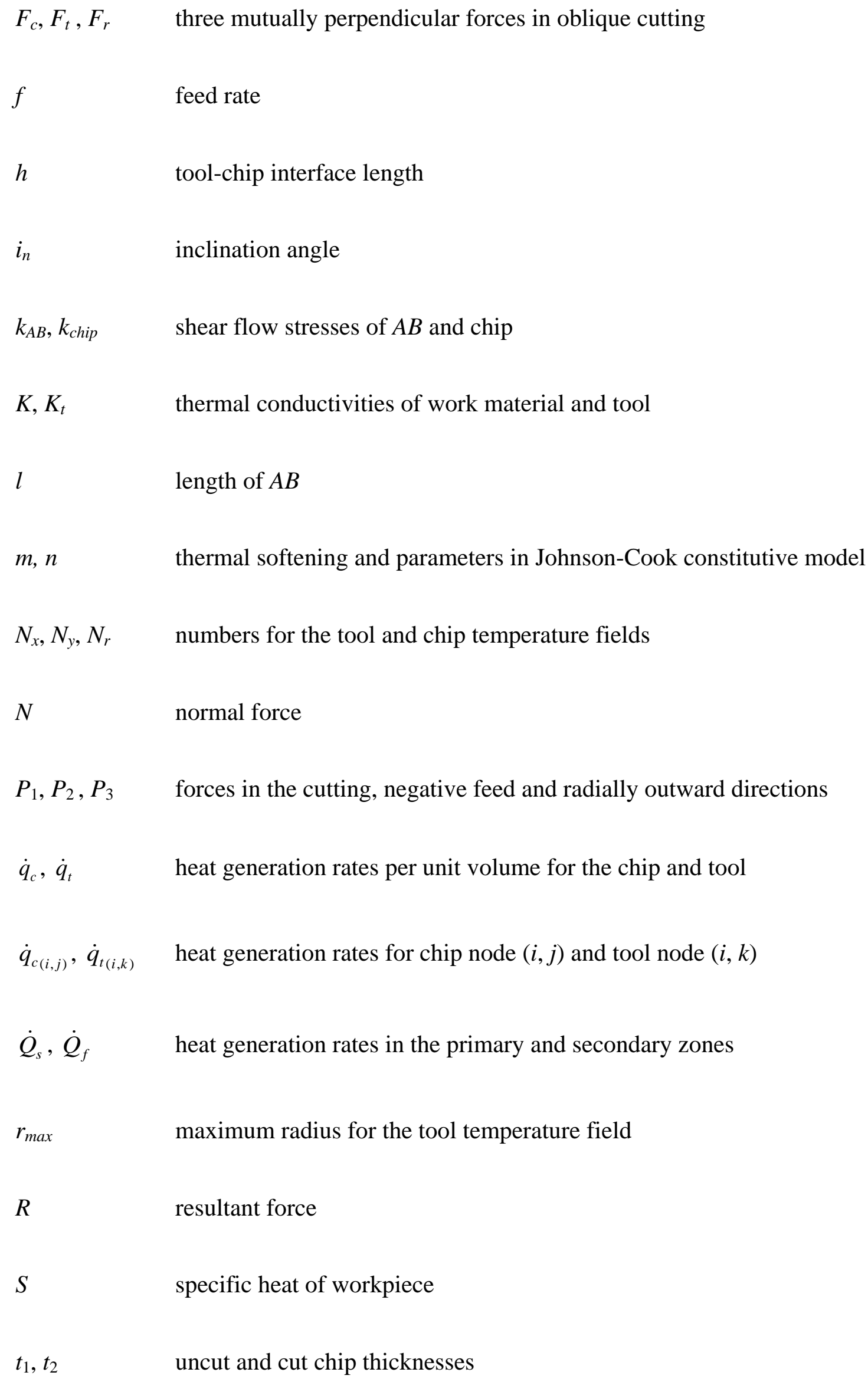




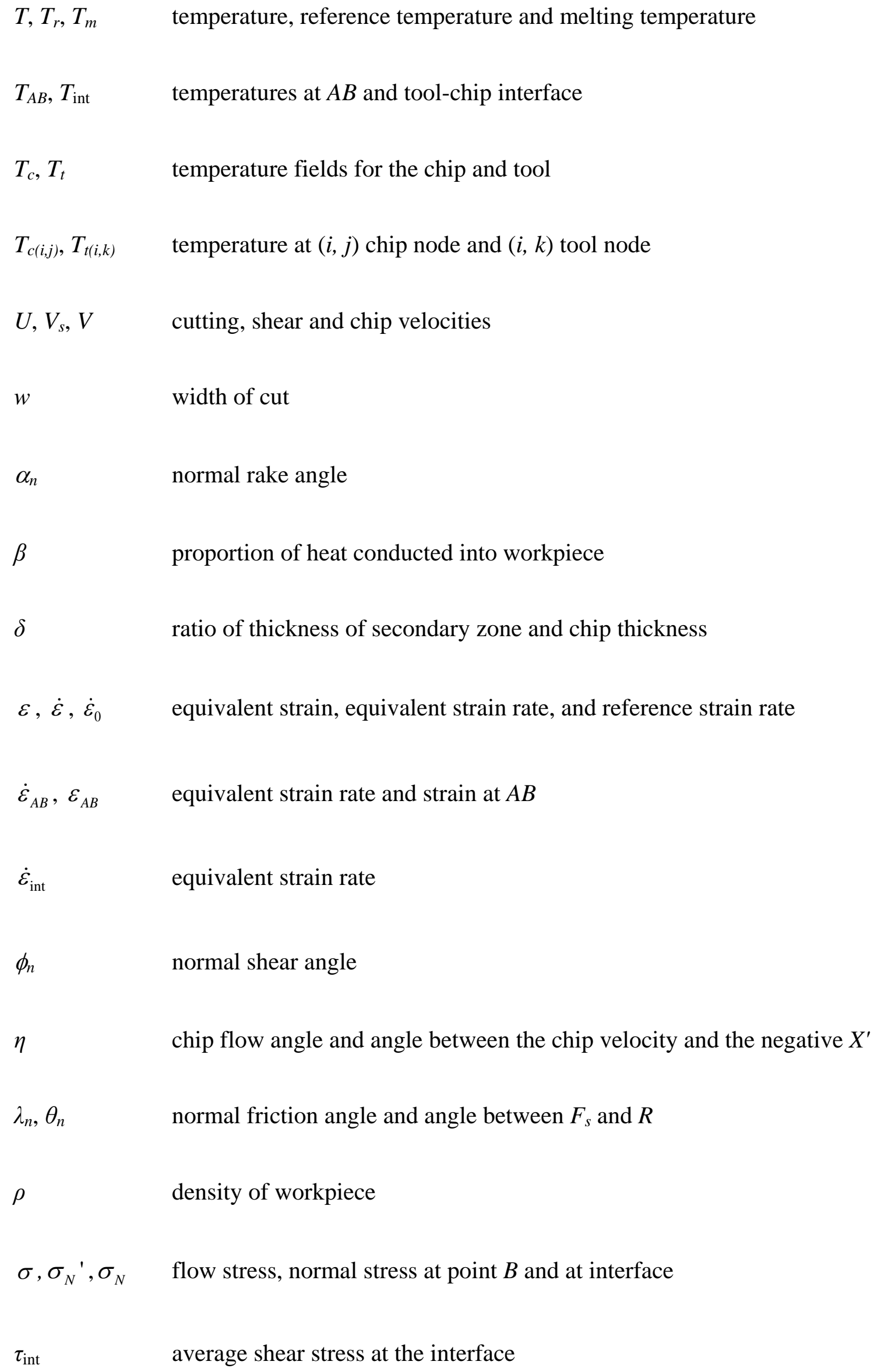




\section{Appendix 2}

The variation of the shear flow stress across the width of the parallel-sided shear zone is different because of the use of Johnson-Cook material model. It can be evaluated as follows

$$
\frac{\Delta k}{\Delta s_{2}}=\frac{d k}{d s_{2}}=\frac{d k}{d \gamma} \frac{d \gamma}{d t} \frac{d t}{d s_{2}}
$$

From equation (1), it can be obtained at $A B$ that

$$
\begin{aligned}
& \frac{d k}{d \gamma}=\frac{d \sigma / \sqrt{3}}{\sqrt{3} d \varepsilon}=\frac{n B \varepsilon_{A B}{ }^{n-1}}{\sqrt{3}\left(A+B \varepsilon_{A B}{ }^{n}\right)} k_{A B} \\
& \frac{d \gamma}{d t}=\dot{\gamma}_{A B}=C_{0} \frac{V_{s}}{l} \\
& \frac{d t}{d s_{2}}=\frac{1}{U \sin \phi}
\end{aligned}
$$

Substituting equations (29) to (31) into equation (28) yields

$$
\frac{\Delta k}{\Delta s_{2}}=C_{0} \frac{2 k_{A B} n B \varepsilon_{A B}{ }^{n}}{\left(A+B \varepsilon_{A B}{ }^{n}\right) l}
$$

In Oxley’s theory,

$$
\tan \theta_{n}=1+2\left(\frac{\pi}{4}-\phi_{n}\right)-\frac{\Delta k l}{2 k_{A B} \Delta s_{2}}
$$

Substituting equation (32) into equation (33) gives

$$
\theta_{n}=\tan ^{-1}\left(1+2\left(\frac{\pi}{4}-\phi_{n}\right)-C_{0} \frac{B \varepsilon_{A B}{ }^{n}}{A+B \varepsilon_{A B}{ }^{n}}\right)
$$

Similarly, the tool-chip contact length $h$ and the normal stress $\sigma_{N}{ }^{\prime}$ at point $B$ should also be updated as

$$
h=\frac{t_{1} \sin \theta}{\cos \lambda_{n} \sin \phi_{n}}\left\{1+\frac{C_{0} \frac{B \varepsilon_{A B}{ }^{n}}{A+B \varepsilon_{A B}{ }^{n}}}{3\left[1+2\left(\frac{\pi}{4}-\phi\right)-C_{0} \frac{B \varepsilon_{A B}{ }^{n}}{A+B \varepsilon_{A B}{ }^{n}}\right]}\right\}
$$




$$
\sigma_{N}{ }^{\prime}=k_{A B}\left(1+\frac{\pi}{4}-2 \alpha-2 C_{0} \frac{B \varepsilon_{A B}^{n}}{A+B \varepsilon_{A B}^{n}}\right)
$$

\section{Figures}

Figure 1. The deformation pattern in serrated chip formation. ${ }^{23}$

Figure 2. Chip formation model in orthogonal cutting.

Figure 3. Finite difference solution (a) chip and tool meshing (b) nodal network for chip (c) nodal network for tool.

Figure 4. Flow chart of the determination of the tool and chip thermal fields.

Figure 5. Flow chart of the proposed model.

Figure 6. Experimental setup (a) workpiece (b) turning setup.

Figure 7. Comparison of predicted and experimental results under different cutting speeds (a) cutting force $F_{c}(\mathrm{~b})$ thrust force $F_{t}(\mathrm{c})$ chip thickness.

Figure 8. Comparison of predicted and experimental results under different feed rates (a) cutting force $F_{c}(\mathrm{~b})$ thrust force $F_{t}(\mathrm{c})$ chip thickness.

Figure 9. Thermal results for test 2 in Table 2 (a) heat partition $B_{i}$ (b) thermal field

Figure 10. Comparison of predicted and experimental results for the work done by Sima and Ozel $^{17}$ (a) forces $F_{c}$ and $F_{t}(\mathrm{~b})$ chip thickness.

Figure 11. Comparison of the maximum tool-chip interface temperature

Figure 12.Thermal field for test 3 in Table 3. 


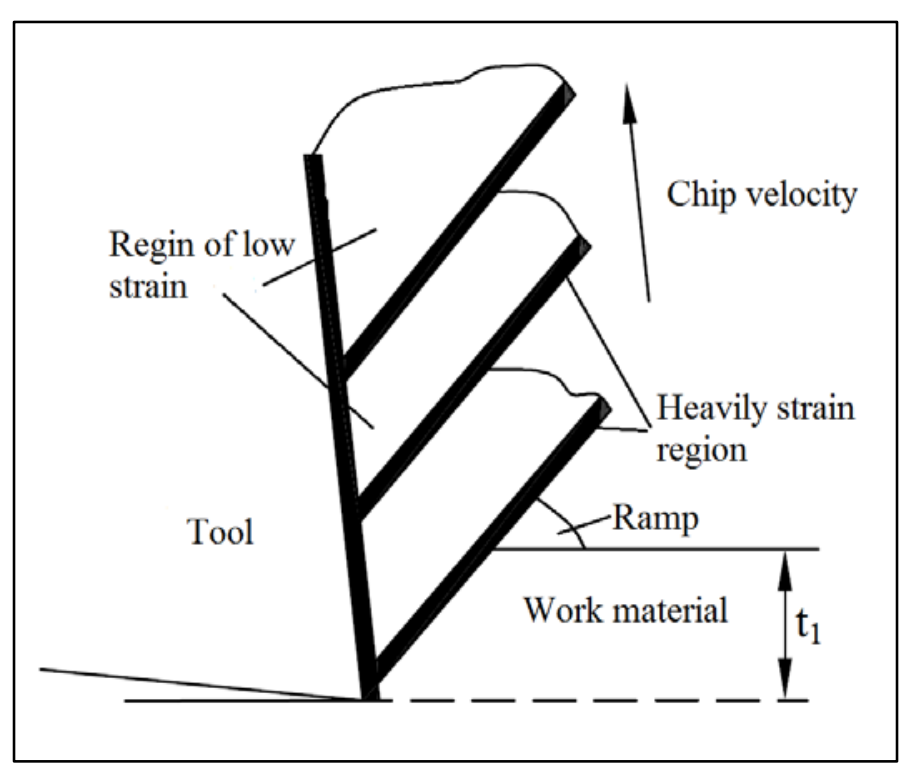

Figure 1.

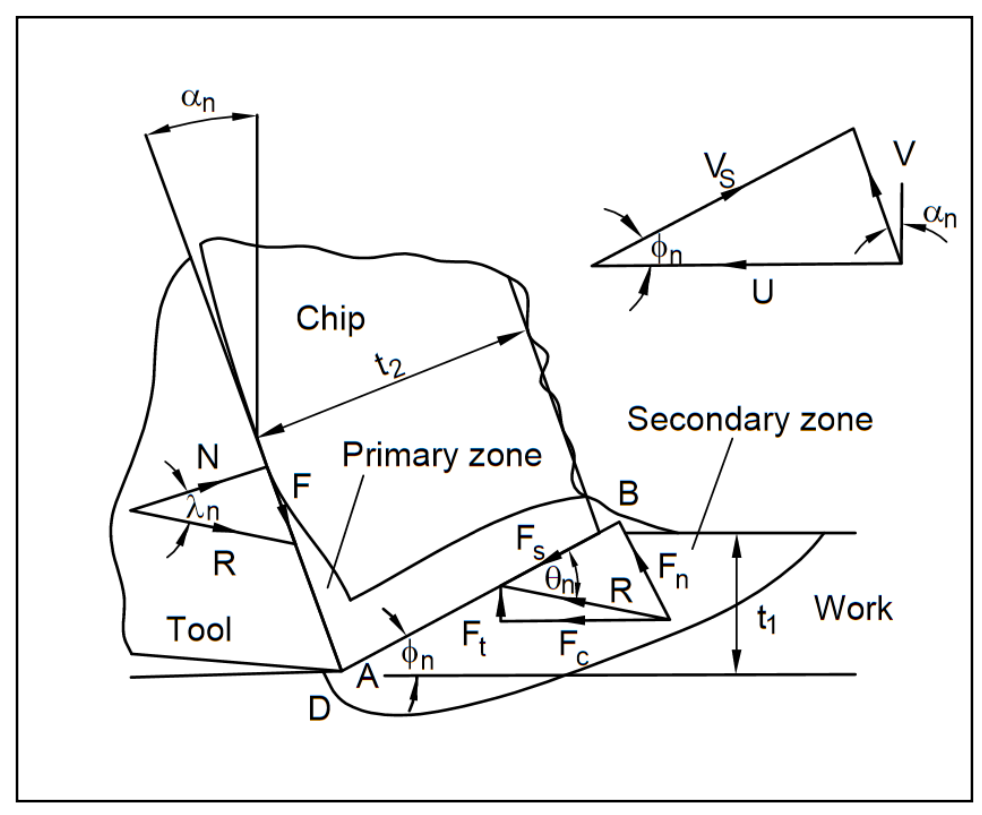

Figure 2.

24 

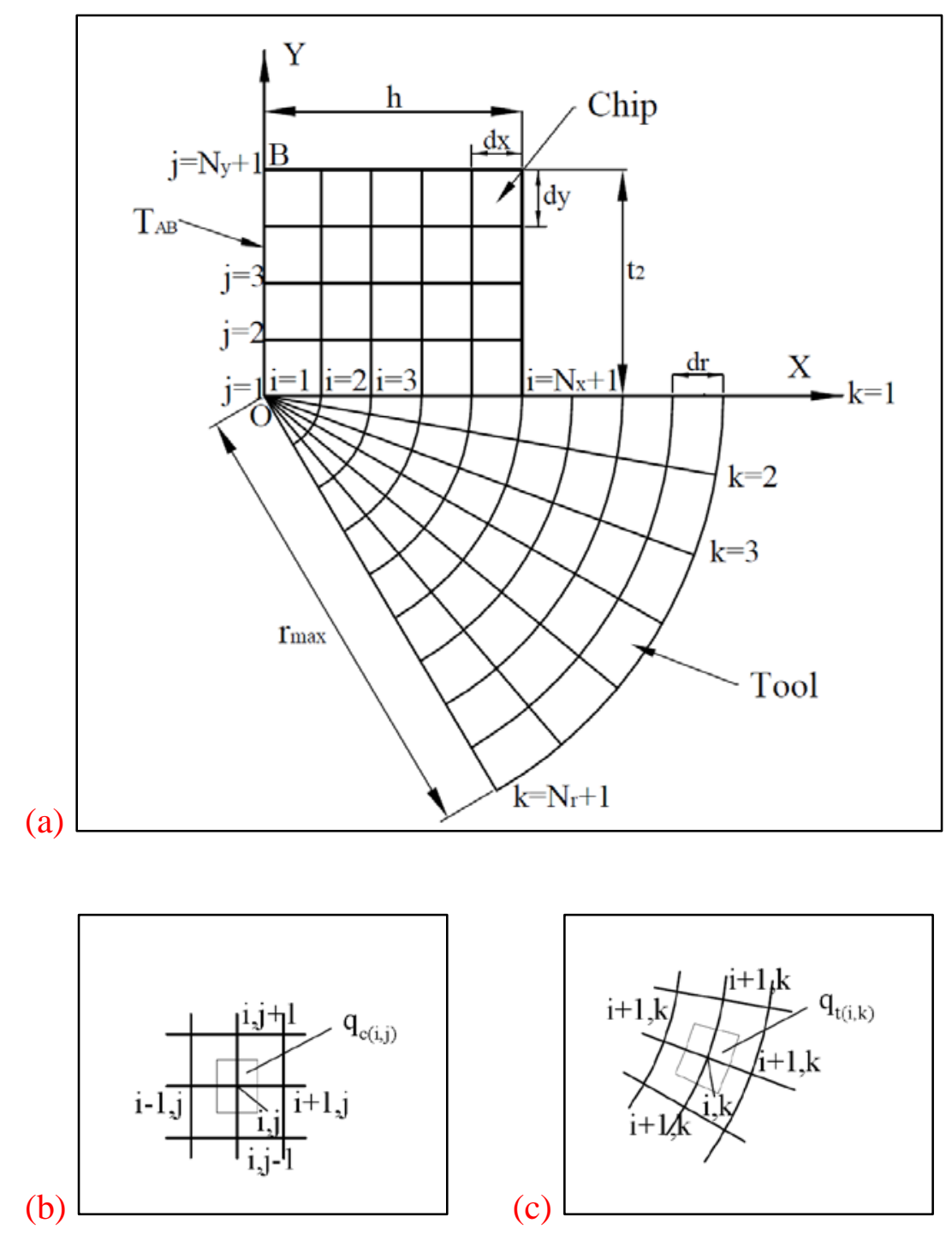

Figure 3 


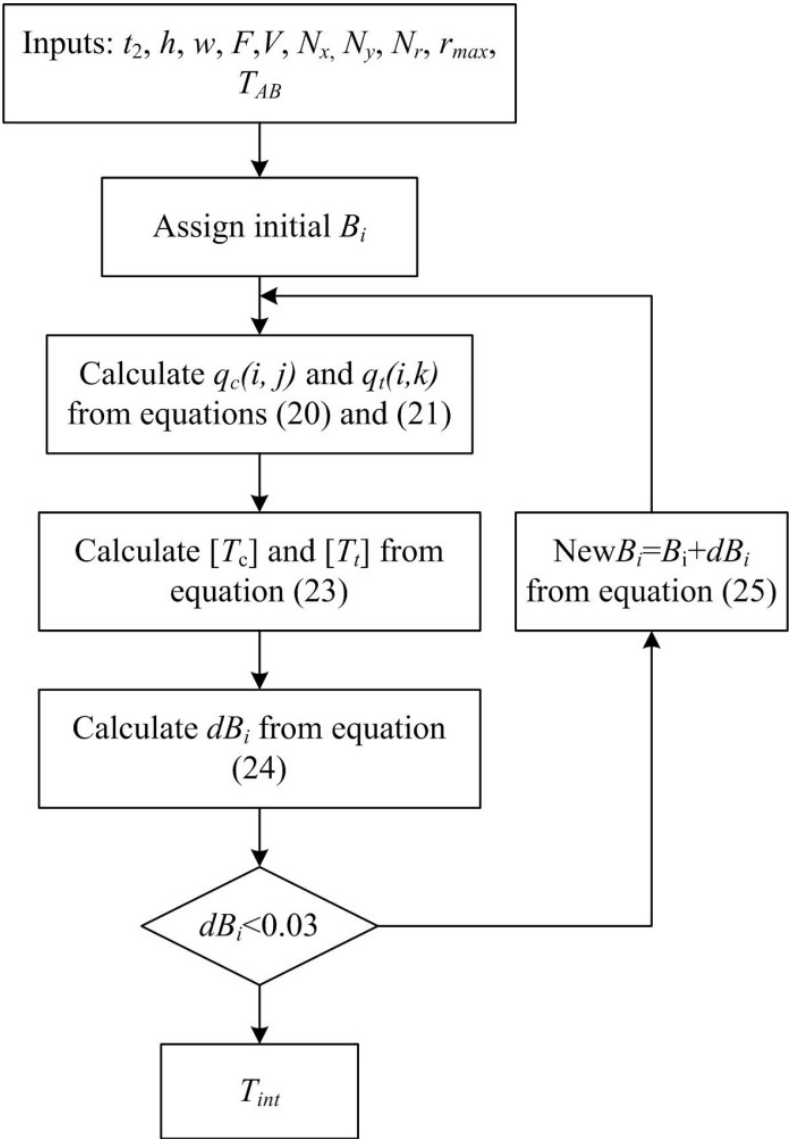

Figure 4. 


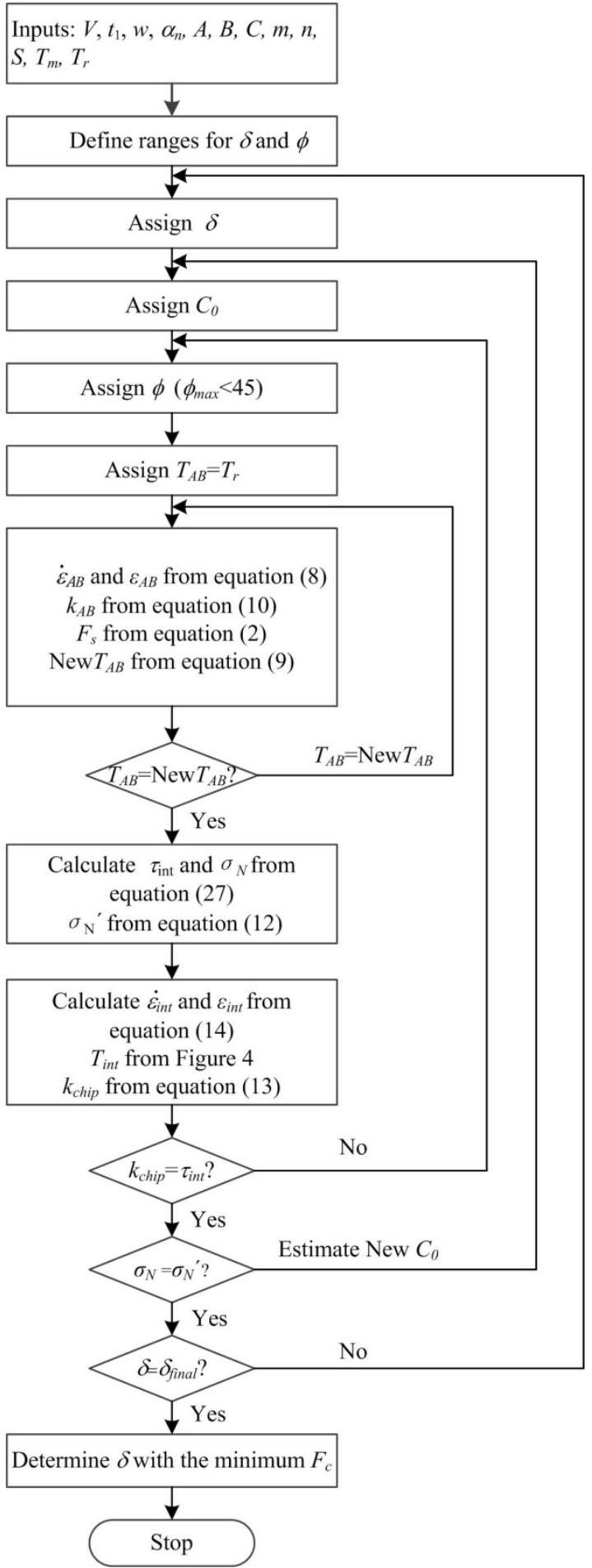

Figure 5. 

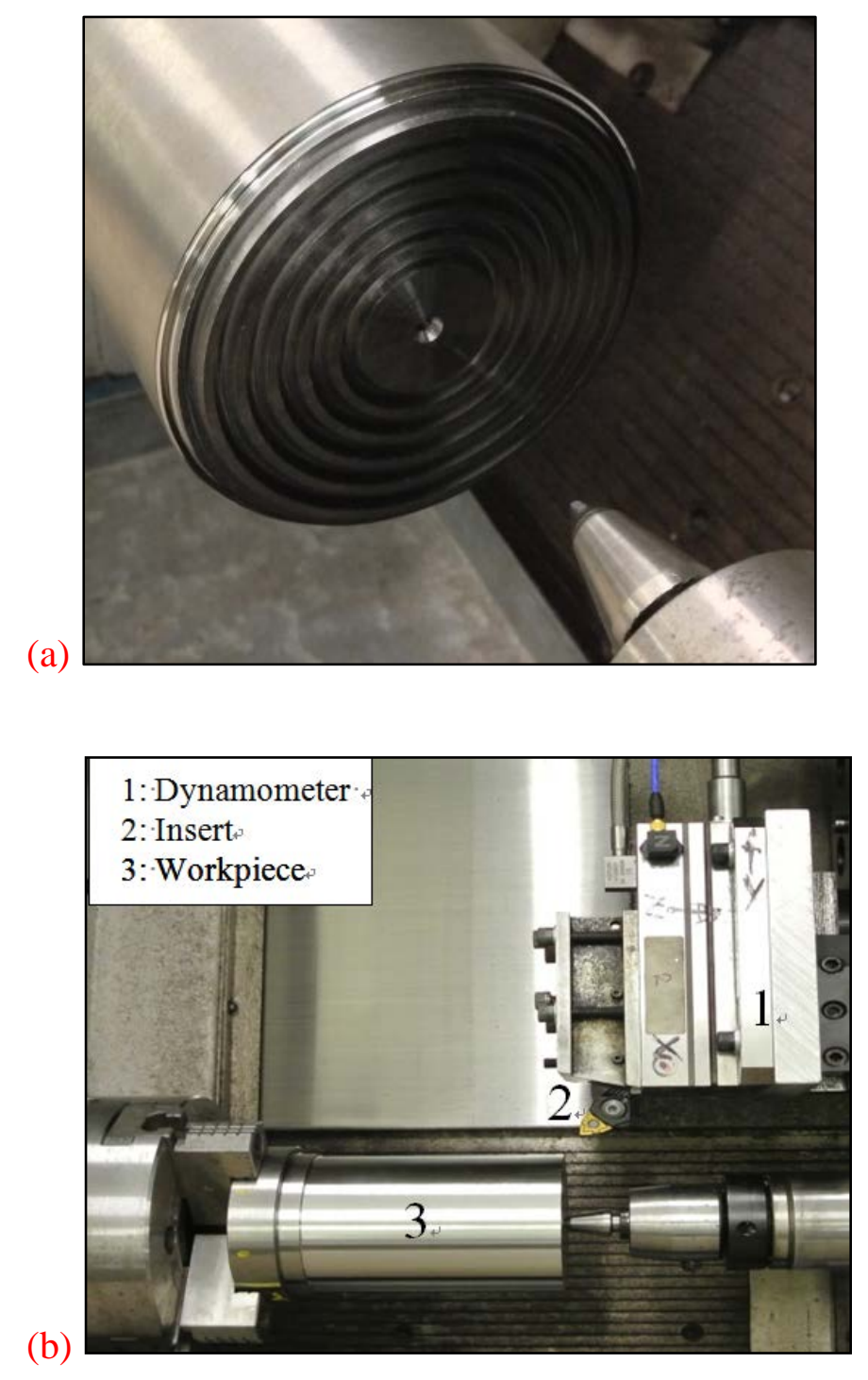

Figure 6. 

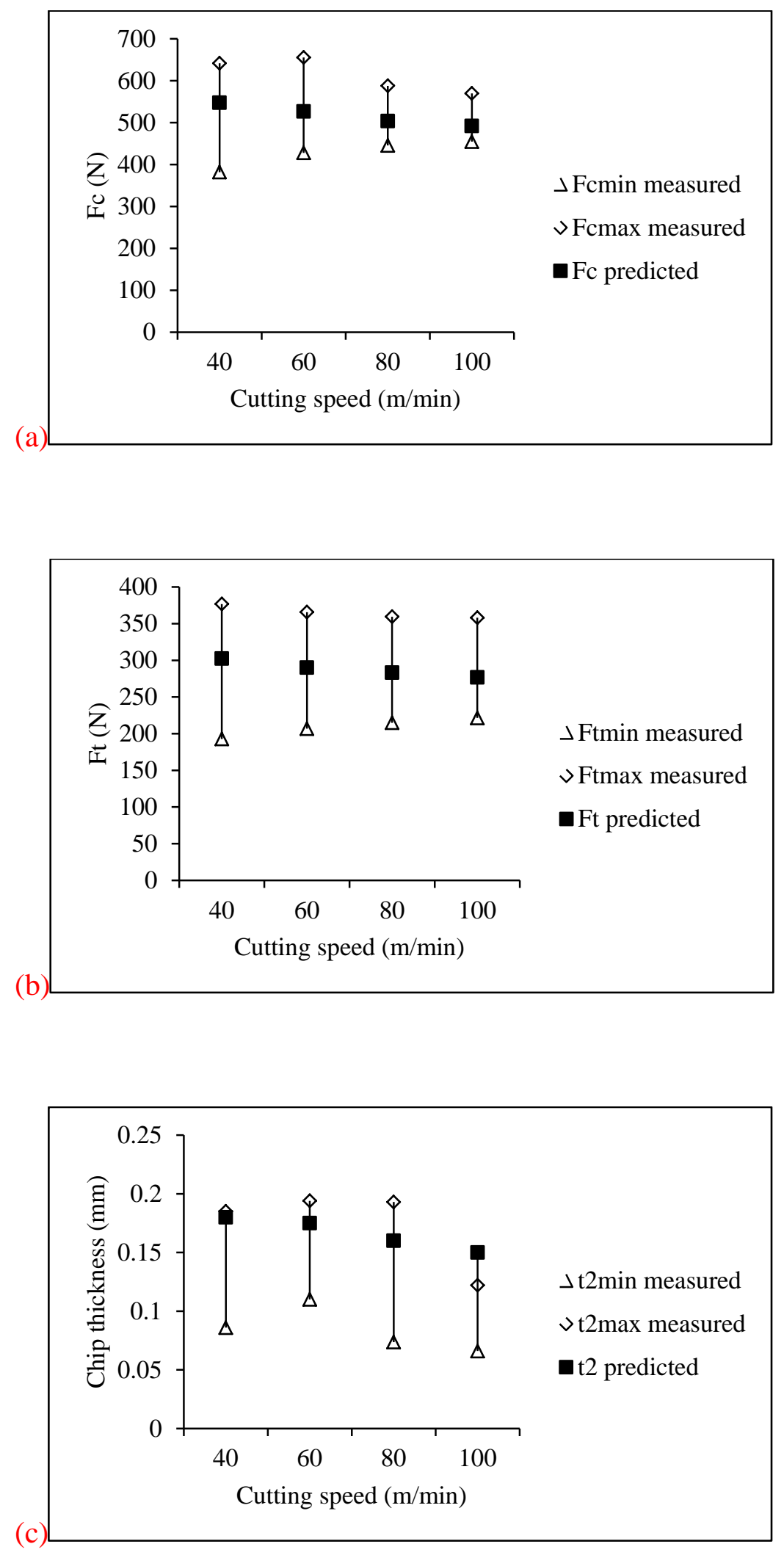

Figure 7. 

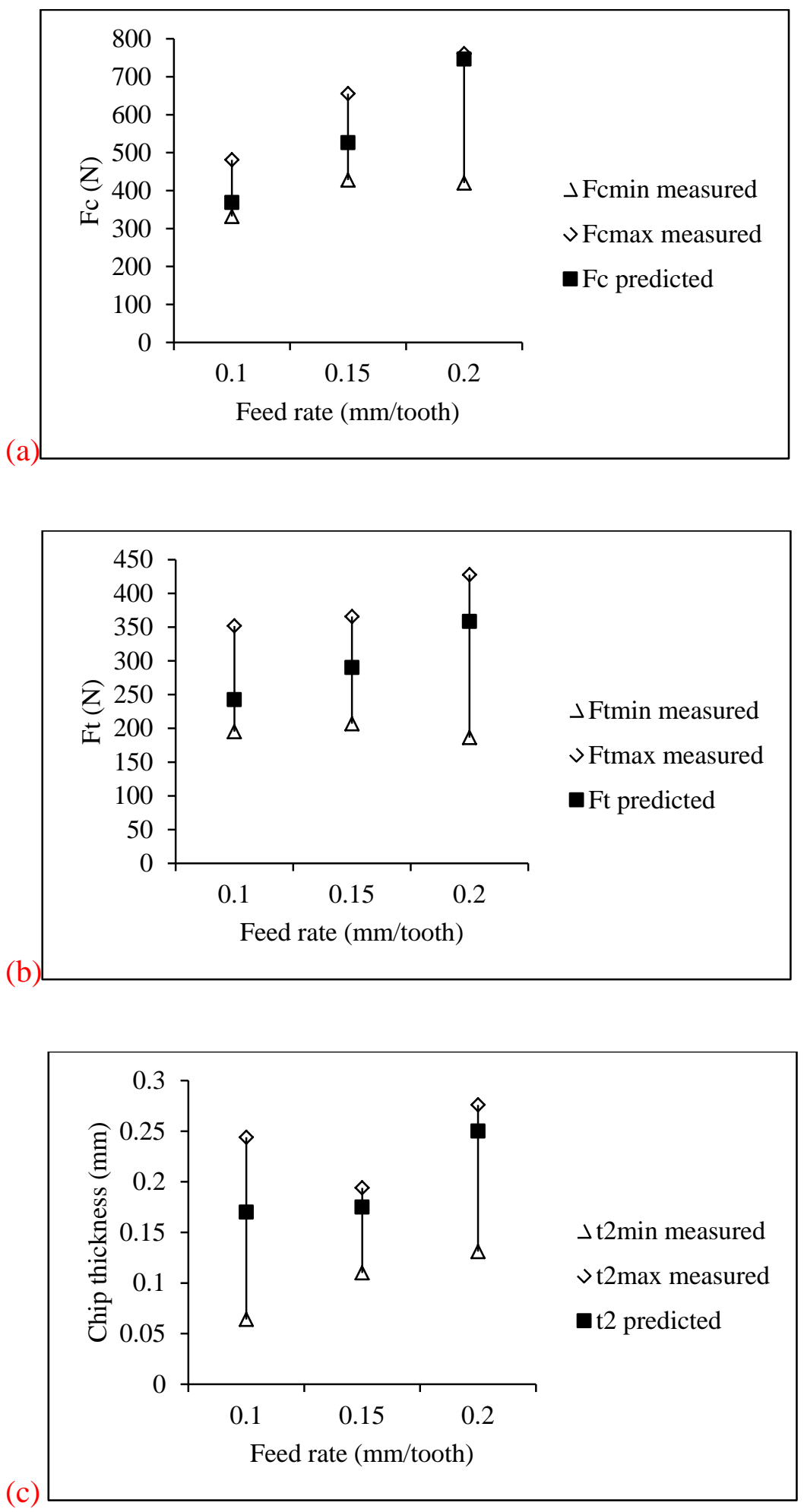

Figure 8. 

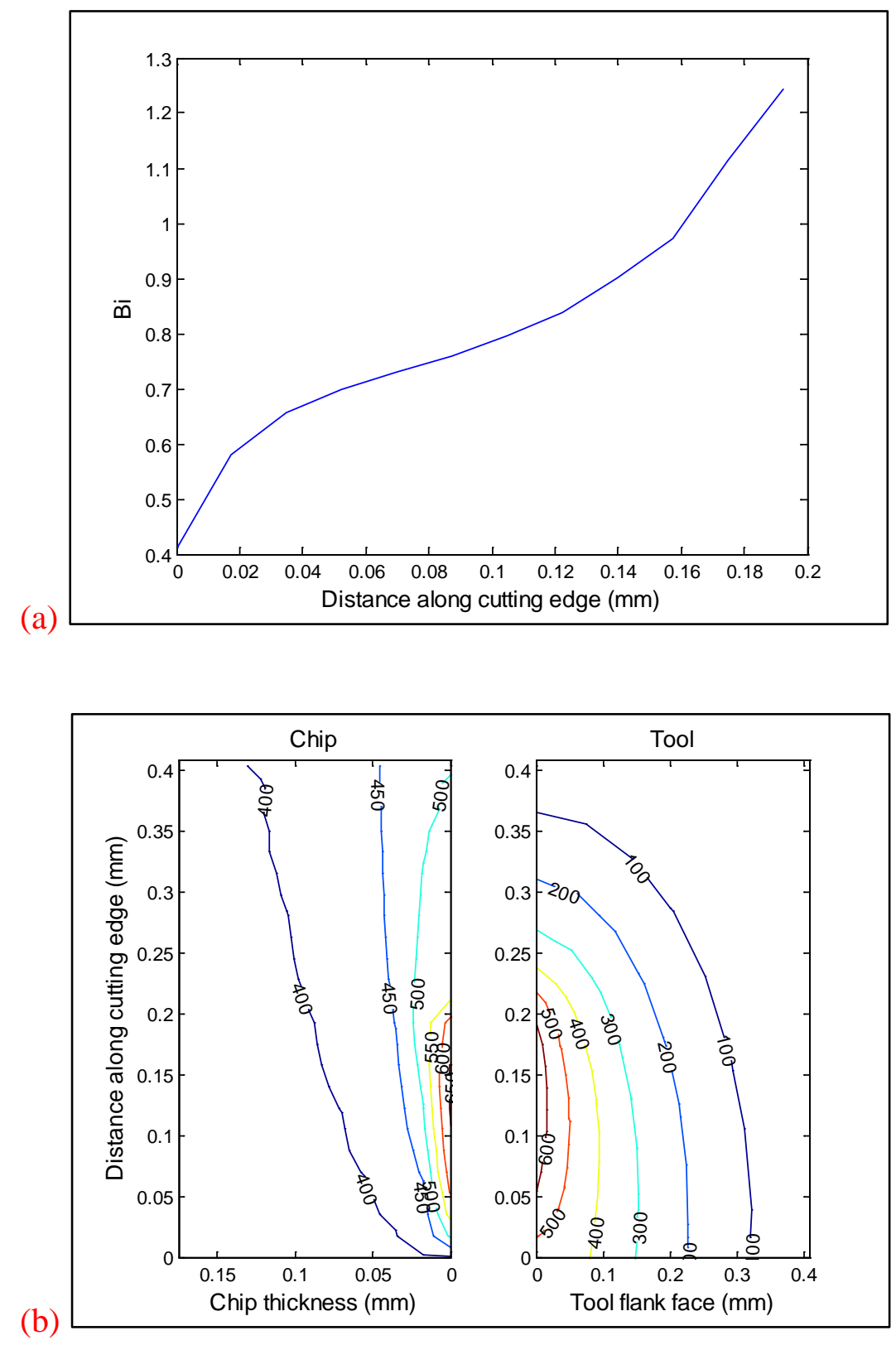

Figure 9. 

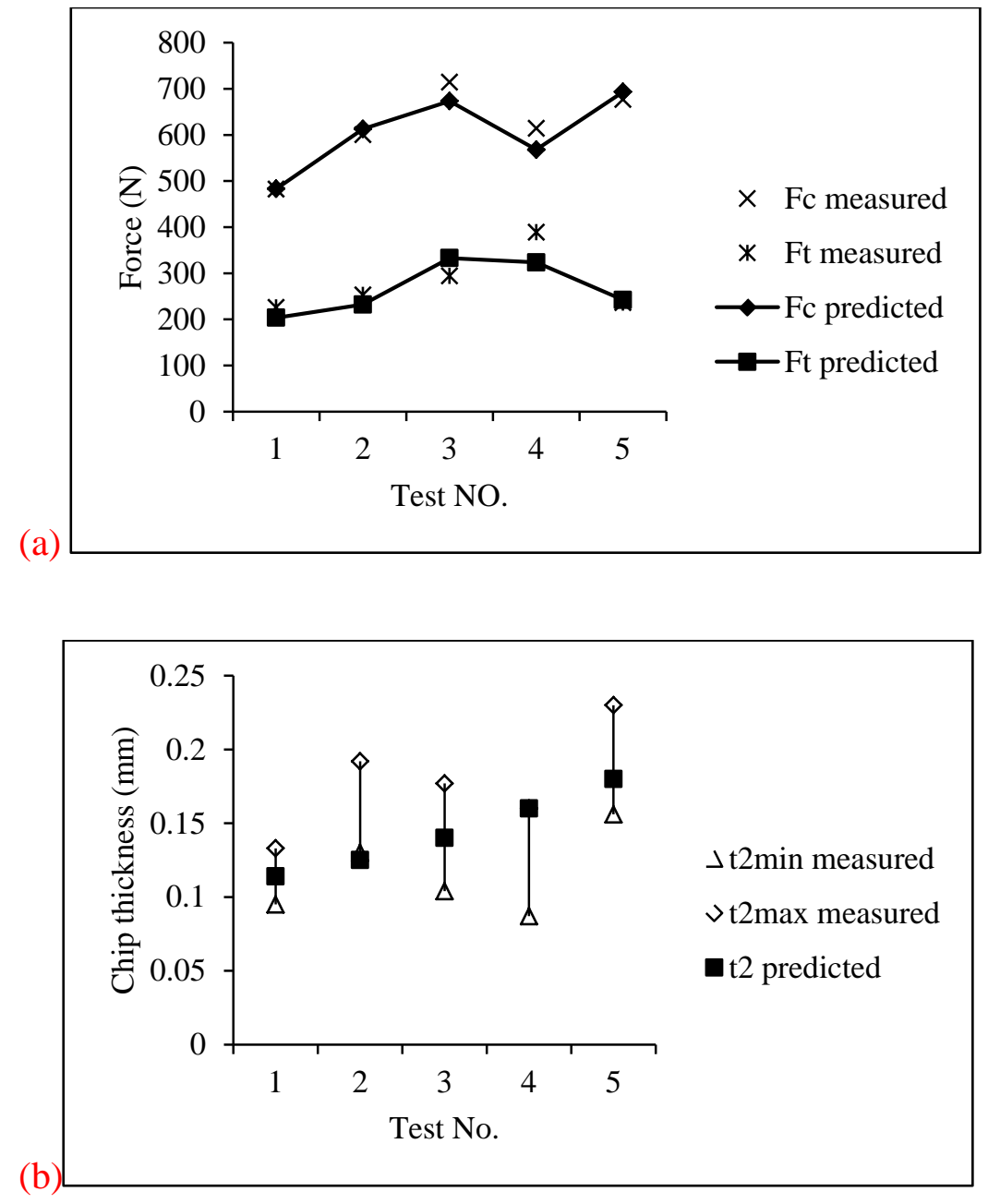

Figure 10. 


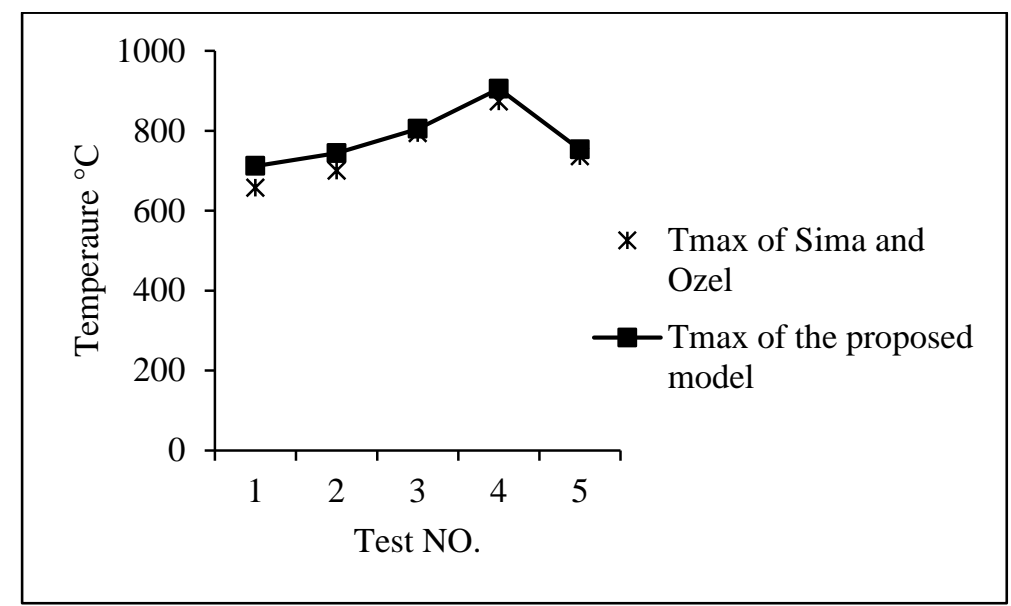

Figure 11.

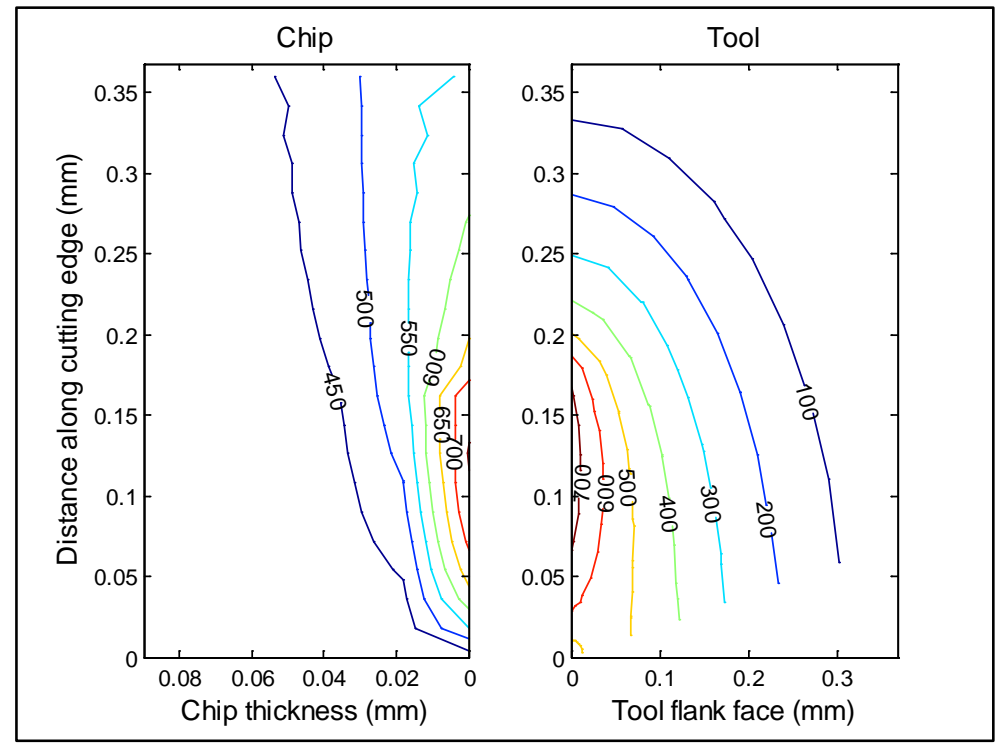

Figure 12. 


\section{Tables}

Table 1. Johnson-Cook model parameters for different materials.

Table 2. Cutting conditions and computed variables $\left(\alpha_{n}=-6^{\circ}\right.$ and $\left.w=2 \mathrm{~mm}\right)$.

Table 3. Cutting conditions $(w=3.175 \mathrm{~mm})$.

Table 2

\begin{tabular}{lcccccc}
\hline Material & $T_{m}\left({ }^{\circ} \mathrm{C}\right)$ & $A(\mathrm{MPa})$ & $B(\mathrm{MPa})$ & $C$ & $n$ & $m$ \\
\hline AISI 1045 & & & & & & \\
Ti6Al4V & 1460 & 553.1 & 600.8 & 0.0134 & 0.234 & 1 \\
& 1630 & 862.5 & 331.2 & 0.012 & 0.34 & 0.8 \\
\hline
\end{tabular}

Table 2

\begin{tabular}{ccccc}
\hline Test & $\begin{array}{c}\mathrm{f} \\
(\mathrm{m} / \mathrm{min})\end{array}$ & $\begin{array}{c}T_{A B} \\
(\mathrm{~mm} / \mathrm{rev})\end{array}$ & $\begin{array}{c}T_{\max } \\
\left({ }^{\circ} \mathrm{C}\right)\end{array}$ & $\left({ }^{\circ} \mathrm{C}\right)$ \\
\hline 1 & 40 & 0.15 & 399 & 524 \\
2 & 60 & 0.15 & 451 & 670 \\
3 & 80 & 0.15 & 560 & 879 \\
4 & 100 & 0.15 & 607 & 1031 \\
5 & 60 & 0.10 & 435 & 507 \\
6 & 60 & 0.20 & 504 & 921 \\
\hline
\end{tabular}

Table 3

\begin{tabular}{ccccc}
\hline Test & $\begin{array}{c}\alpha_{n} \\
\left({ }^{\circ}\right)\end{array}$ & $\begin{array}{c}U \\
(\mathrm{~m} / \mathrm{min})\end{array}$ & $\begin{array}{c}f \\
(\mathrm{~mm} / \mathrm{rev})\end{array}$ & $\begin{array}{c}T_{A B} \\
\left({ }^{\circ} \mathrm{C}\right)\end{array}$ \\
\hline 1 & 0 & 121.9 & 0.075 & 373 \\
2 & 0 & 121.9 & 0.1 & 472 \\
3 & 0 & 121.9 & 0.127 & 500 \\
4 & 0 & 240.8 & 0.1 & 458 \\
5 & 5 & 121.9 & 0.127 & 422 \\
\hline
\end{tabular}

